\title{
Producción de materiales didácticos para una comunicación en valores a través de imágenes de periódicos
}

\author{
Production of didactic materials for a communication in values through \\ newspaper images
}

\begin{abstract}
Víctor Gonzalo Balboa
Recibido junio 2020

Arbitrado julio 2020

Publicado septiembre 2020

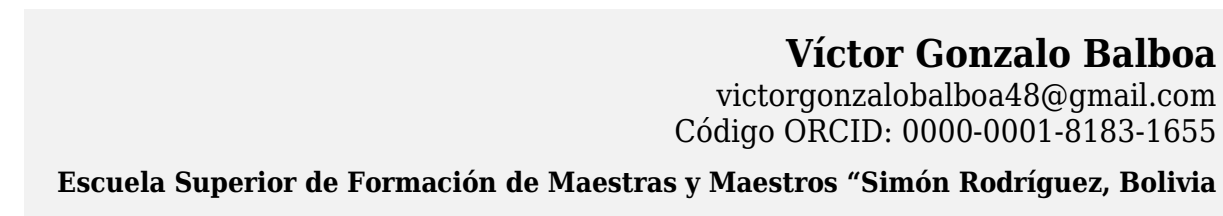

\section{Resumen}

El propósito de la presente investigación estuvo fundamentado en el empleo de estrategias didácticas para mejorar el aprendizaje en los estudiantes de la Unidad Educativa "Toribio Claure Montaño". La estrategia didáctica empleada fue el uso de periódico para la construcción de conceptos y definiciones, generando así un aprendizaje significativo. El enfoque fue el cualitativo y el diseño fue de campo. La muestra fue el equipo de trabajo del 1ero B de secundaria donde se incluyeron estudiantes, representantes y docentes. La técnica que se utilizó fue la entrevista en profundidad y el cuestionario de preguntas abiertas. Los resultados apuntaron a que el empleo del periódico como estrategia didáctica tiene un impacto muy positivo en la población porque permitió a los docentes aprender una nueva estrategia de enseñanza aprendizaje, propició un trabajo en equipo entre la comunidad educativa y los educandos desarrollaron habilidades investigativas, reflexivas, críticas, de comunicación, trabajo en equipo, motivación y de seguridad.

\footnotetext{
Abstract

The purpose of this research was based on the use of didactic strategies to improve learning in the students of the "Toribio Claure Montaño" Educational Unit. The didactic strategy used was the use of newspapers for the construction of concepts and definitions, thus generating significant learning. The approach was qualitative and the design was field. The sample was the work team of the 1st B of secondary school where students, representatives and teachers were included. The technique used was the in-depth interview and the openended questionnaire. The results pointed out that the use of the newspaper as a didactic strategy has a very positive impact on the population because it allowed teachers to learn a new teachinglearning strategy, it fostered teamwork between the educational community and the students developed investigative and reflective skills, criticism, communication, teamwork, motivation and safety.
}

Palabras clave:

Aprendizaje significativo; estrategias didácticas; periódico 


\section{INTRODUCCIÓN}

L a calidad educativa es prioridad de todos y en Bolivia no es la excepción. Los planes y programas de estudio en los que se basa la educación actual, están regidos por las exigencias del quehacer. El docente es uno de los pilares básicos para el logro de la calidad educativa y aunque son múltiples las actividades que se realizan en la escuela, están en primer plano las relacionadas con el proceso de enseñanza-aprendizaje.

Para mejorar este proceso es necesario comprender cómo es la práctica educativa desde la perspectiva de los participantes. Conocer y analizar cuáles son las estrategias de enseñanza que utilizan los docentes, cómo se eligen, si se busca diversificar su uso, si se llevan cursos de capacitación o si se tienen interés en seguirse capacitando, si se toman en cuenta los estilos de aprendizaje de los alumnos, si se busca a través de las actividades que diseñan una mayor disposición hacia el aprendizaje, si se le da importancia al material didáctico o si lo diseña, si sabe evaluar, las estrategias que pone en práctica, entre otros.

De igual forma, es importante conocer el punto de vista de los alumnos acerca de las estrategias de enseñanza que utiliza el docente, cuáles son las estrategias que más se utilizan durante las clases, qué tipo de estrategias les motivarían a participar o a seguir investigando respecto a un tema determinado, cómo les gustaría aprender, qué tipo de material didáctico les motiva a participar durante la clase, entre otros. Estas consideraciones nos pueden proporcionar información relevante acerca de las fallas y los aciertos en el proceso de enseñanza aprendizaje.

La presente investigación no pretende ser una fórmula mágica para resolver problemas de aprendizaje que se presentan en el aula ni descartar otras estrategias de enseñanza, pero sí es una opción novedosa y práctica para abordar temas con mayor dificultad en el aprendizaje. La viabilidad del uso de material didáctico diseñado en la institución educativa puede ser una forma de motivar al alumno para aprender procesos que se le dificultan, dejando atrás el aprendizaje memorístico de conceptos y permitiéndole el logro de un conocimiento real o significativo, el cual pueda aplicar en su vida cotidiana, por lo que puede ser de gran ayuda en el proceso de enseñanza. 
Por otro lado, la continua formación de maestros en el actual contexto educativo nos lleva a valorar las experiencias creativas en la transformación de la práctica educativa que permite objetivar las aspiraciones del Modelo Educativo Socio-productivo. Es por eso que la producción de conocimientos es la forma en la que el maestro produce conocimientos permanentes para la realidad de su contexto, desde su práctica pedagógica, que genere una educación que responda a nuestras realidades y permita formar estudiantes críticos, reflexivos y autocríticos capaces de producir un conocimiento significativo aplicable a su vida diaria.

Así mismo el trabajo desarrollado involucra a padres de familia, estudiantes, maestros y autoridades quienes con el afán de participar en el proceso del desarrollo de la experiencia, están comprometidos a conocer, desarrollar y valorar las aptitudes, habilidades y destrezas de sus hijos dentro y fuera del entorno educativo, el cual ayudará a afianzar en el estudiante la expresión oral, escrita e interpretativa.

Con esta propuesta es necesario que todos los sujetos involucrados en la cuestión educativa actual concienticen la importancia que tiene participar en el ámbito educativo, en tanto con sus experiencias enriquecedoras y formadoras, así como los problemas que éste conlleva para la búsqueda de caminos alternativos, flexibles y transitables que permitan beneficiar a los educandos y brindarles una formación de calidad.

Dicho esto, el trabajo docente ha estado marcado por exigencias y responsabilidades educativas que la sociedad misma demanda; es por ello que el docente busca auxiliares educativos como el "material didáctico" para contribuir al desarrollo del educando en el proceso de enseñanza aprendizaje, lo más íntegramente posible, haciendo énfasis en su carácter integral, que abarca todos los aspectos de la realidad. Es decir, todo lo anterior para optimizar la calidad de educación en una escuela de vida.

Cabe agregar que el concepto "vida" no es puramente biológico; para vivir hay que producir los medios materiales necesarios; la existencia del hombre está condicionada a la actividad que realiza para hacerla posible. La actividad es la que hizo al hombre, dio lugar al razonamiento, permitió el crecimiento del cerebro. La actividad transforma a la naturaleza y por consiguiente transforma al hombre mismo, el progreso de las generaciones, la continua asimilación del conocimiento. Por todo eso, la educación es un elemento 
esencialmente creador, formador de conciencia, de inteligencia, de "humanidad" en el más amplio sentido.

De este modo, la utilización del periódico como material didáctico tiene una gran riqueza y enormes ventajas. En primer lugar, rescata la participación del educando en el proceso educativo a través de la obtención y selección del material, haciéndole más sencilla su manipulación, así como más significativos los aprendizajes; en segundo lugar y retomando la posición constructivista del conocimiento, este tipo de material resulta ser más económico que los materiales comerciales y evita que el docente presente las cosas de forma mecánica y elaborada.

Pero más que hablar de la importancia que pueda tener el recurrir a la utilización de materiales didácticos como el periódico, en un sentido meramente económico, la posible valía de éstos pudiera estar en la forma en cómo el docente de la educación secundaria recurre a ellos según la finalidad en que se basa la educación y formación del nivel el desarrollo integral de todo aspecto en el educando, es decir, el social, psicológico, afectivo, intelectual y físico.

Es por tanto que la implementación del periódico como material didáctico genera procesos de producción de conocimientos orientados al desarrollo y fortalecimiento del modelo educativo acorde a la Ley № 070, a través de la sistematización de la experiencia traducida en la producción de materiales educativos, mediante la utilización de metodologías, instrumentos y técnicas pertinentes, fortaleciendo el trabajo solidario y comunitario para profundizar la transformación de las prácticas educativas.

De esta forma es necesario desarrollar procesos de producción de conocimientos que partan de nuestras experiencias educativas, analizando, investigando y sistematizando, en el marco de la interrelación solidaria y de respeto, para transformar nuestra práctica educativa orientada hacia una educación productiva, que permita incorporar valores de complementariedad y reciprocidad, y que a la vez permita incorporar de manera pertinente cambios en nuestra práctica educativa.

Dicha práctica debe estar orientada hacia una educación pertinente, con alumnos, fuertes y constructores de sus propios aprendizajes reflexivos, críticos y dinámicos con su alto grado de autoestima que les permita lograr sus objetivos, en base a valores y principios, fortalecidos por maestros altamente capacitados en el 
nuevo enfoque y con la participación de padres de familia, comprometidos en todo el proceso de enseñanza-aprendizaje de sus hijos, contando con una infraestructura adecuada que proteja la salud y bienestar de los educados.

Por esta razón, nuestra visión a largo plazo es desarrollar hábitos de lectura comprensiva, reflexiva, analítica, investigativa y crítica aplicando nuevas estrategias en el aula y fuera de ella, valorando y estimulando el trabajo de los educados, docentes y padres de familia, para construir una comunidad educativa líder que ofrezca un servicio de calidad en beneficio de la sociedad. En pocas palabras, mejorar la calidad educativa consecuentemente, para ofrecer a nuestros estudiantes mejores oportunidades.

Para lograr este propósito, la presente investigación propone la implementación de materiales didácticos, también denominados auxiliares didácticos o medios didácticos que pueden ser cualquier tipo de dispositivo diseñado y elaborado con la intención de facilitar un proceso de enseñanza y aprendizaje.

Así mismo los materiales didácticos pueden proporcionar información, guían los aprendizajes, ejercitan las habilidades, ayudan en la motivación y proporcionan entornos para la expresión y creación. De este modo, de acuerdo con la Unidad de formación №7 (2013) los materiales educativos "son dispositivos que contienen el contenido que se pretende desarrollar en la experiencia pedagógica. Por otro lado, los materiales educativos son todos los objetos que sirven para educar, no solo para transmitir conocimientos sino también para producirlos" (p.12).

Por tanto, los materiales didácticos son un material de apoyo para el desarrollo de las actividades y en algunas ocasiones los estudiantes descubren algunas de sus cualidades ocultas que tienen. Por eso la interacción maestros y alumnos debe ser de manera participativa y dinámica. También hay que resaltar que, en la elaboración de materiales de producción, por ejemplo, se puede pedir la colaboración de padres o madres de familia cuyos oficios estén relacionados con el material que quiere producirse como mecánicos, carpinteros, electricistas, albañiles, y otros, logrando así articularla dinámica laboral del contexto a la producción de conocimiento en la escuela" (Unidad de Formación № 7. 2013 p.22).

En consecuencia, en este proceso de deben generar nuevas formas de aprender, investigar y principalmente desarrollar las dimensiones Ser-Saber-Hacer-Decidir, a partir de la articulación de 
las estrategias metodológicas. Estas son un conjunto de actividades articuladas en la Practica-Teoría-Valoración-Producción. (Unidad de Formación № 5 p. 20-22).

\section{ANTECEDENTES DE LA INVESTIGACIÓN}

$\mathrm{E}$ n cuanto a los antecedentes de la investigación, los mismos están fundamentados en la experiencia obtenida durante un seminario taller realizado en el año 2012 sobre "Estrategias innovadoras de aprendizaje" dirigido por la Licenciada Margarita Hermosa quien, incentivando a la reflexión y motivación, desarrolló la estrategia del periódico formando así un aporte muy importante sobre la educación significativa.

Con esta parte de la reflexión, la Licenciada argumentó sobre la carencia de valores en la población estudiantil, la familia y la comunidad en general, indicando que el fin de la educación es crear estudiantes reflexivos, críticos, creativos, productivos, capaces de analizar y comunicar. En el proceso de la actividad preguntó lo siguiente: ¿Qué significa ser tolerante?, ¿Qué es intolerancia?, ¿Qué es aborto? Y ¿Qué significa maltrato?

Una vez conformados los grupos para realizar la dinámica, le entregó a cada equipo una hoja de papel bond para escribir las palabras a ser interpretadas y conceptualizadas. Luego se procedió a recortar imágenes de los periódicos para representar la palabra y construir conceptos desde las imágenes.

Antes de concluir la sesión, aclaró que todos debían participar en la exposición para explicar lo que se plasmó en el trabajo. Todos los grupos mostraron los paleógrafos en papel bond tamaño pliego e indicaron el significado de la imagen en un concepto claro y sencillo. Durante la actividad todos los participantes mostraron algo de asombro ante la facilidad con que encaminó a todos en el logro de la actividad, con la cual se logró que los maestros aprendieran a construir estrategias innovadoras de aprendizaje.

Luego de esta actividad reflexionó, que el deber de los maestros es mejorarse a sí mismo para poder mejorar luego a sus estudiantes y brindarles un conocimiento significativo. A continuación, un fragmento del relato sobre su experiencia en el taller del investigador Víctor Gonzalo Balboa: 
Para terminar, diré que fue una experiencia muy bonita y favorable para nosotros, puesto que lo pusimos en la práctica y dio un buen resultado. Entonces para mi ahí nace la idea realizar un material didáctico para poder exponer fácilmente y discursar frente al público y generando nuevas ideas o palabras. Esta metodología con el transcurrir del tiempo la mejoré y hoy por hoy tengo educandos que no tienen miedo al exponer, es más se puede decir con nuevas expectativas u nuevos objetivos para lograr sus metas. (Testimonio, s.n.)

Por consiguiente, la experiencia con el material didáctico genera procesos de producción de conocimientos orientados al desarrollo y fortalecimiento del modelo educativo expuesto en la Ley № 070, a través de la de la experiencia la producción de materiales educativos, mediante la utilización de metodologías, instrumentos y técnicas pertinentes, fortaleciendo el trabajo solidario y comunitario para profundizar la transformación de las prácticas educativas traducidas en las cuatro dimensiones del ser, saber, hacer y decidir.

De esta forma se ha desarrollado procesos de producción de conocimientos que aportan y parten de experiencias educativas, analizando, investigando en el marco de la interrelación solidaria y de respeto, para transformar nuestra práctica educativa orientada hacia una educación productiva, que permita incorporar valores de complementariedad y reciprocidad, y que a la vez permita incorporar de manera pertinente cambios en nuestra práctica educativa.

El aporte que presenta esta experiencia es emplear la práctica, teoría, valoración y producción donde los estudiantes experimentaron. Desde ahí se llegó a esta la interpretación iniciando desde lo más básico y terminando hasta lo más complejo su exposición y que nos muestra otros desafíos para seguir creando novedades.

\section{METODOLOGÍA}

$\mathrm{E}$ n este estudio se utilizó la metodología cualitativa, la cual consiste en una forma de investigación donde las cualidades observadas no necesariamente tienen que ser cuantificables mediante análisis estadístico. En este sentido, según HernándezSampier et al., (2014) en este tipo de estudios, el investigador "plantea un problema, pero no sigue un proceso definido claramente. Sus planteamientos iniciales no son tan específicos como en el 
enfoque cuantitativo y las preguntas de investigación no siempre se han conceptualizado ni definido por completo. (p.8)

Dada la naturaleza cualitativa de este estudio, no se plantearon preguntas de investigación propiamente explícitas, sino que se partió de la premisa de una propuesta de estrategia de enseñanza como lo es el uso del periódico para propiciar aprendizajes más significativos en la población de estudio.

En concordancia con Hernández-Sampieri et al., (2014) al respecto de estas investigaciones cualitativas "se procede caso por caso, dato por dato, hasta llegar a una perspectiva más general." Además, la recolección de los datos en este caso, "consiste en obtener las perspectivas y puntos de vista de los participantes, sus emociones, prioridades, experiencias, significados y otros aspectos más bien subjetivos" (p. 8)

Es este orden de ideas, la investigación constituyó un estudio de campo porque se involucró directamente en el fenómeno de indagación. Según Hernández-Sampieri et al., (2014) se trata de un experimento de campo cuando se "lleva a cabo en el ambiente cotidiano de los sujetos. (p.150)

Es por esta razón que efectos de la presente investigación se llevó a cabo la entrevista en profundidad. Esta técnica de recolección de datos permitió conocer la experiencia que tuvieron los participantes en la actividad realizada. Para esta investigación, la preocupación directa del investigador se concentra en las vivencias de los participantes tal como fueron. (Hernández-Sampieri et al., 2014, p.9)

Es pertinente agregar que, la entrevista en profundidad consiste en la sociabilización entre el entrevistador y el especialista en la materia mediante una conversación bastante flexible. Para Taylor y Bogdan (1992) las entrevistas en profundidad "siguen el modelo de una conversación entre iguales, y no de un intercambio formal de preguntas y respuestas" (p. 1) Sin embargo, a pesar de que esta entrevista se caracteriza por ser flexible, se puede hacer de manera estructurada. Por esta razón se empleó un cuestionario de preguntas abiertas como instrumento para dicha técnica. Según HernándezSampieri et al., (2014) las preguntas abiertas "sirven en situaciones donde se desea profundizar una opinión o los motivos de un comportamiento. Su mayor desventaja es que son más difíciles de codificar, clasificar y preparar para el análisis". (p. 405)

En relación con la idea anterior, las preguntas abiertas no delimitan de antemano las alternativas de respuesta del participante, 
por esta razón en la presente investigación no se emplearon métodos estadísticos para su análisis, sino que todo fue descriptivo. Por lo tanto, se puede afirmar que el carácter del presente estudio fue descriptivo. En concordancia con Palella y Martins (2010), el propósito "es el de interpretar realidades de hecho, incluyendo descripción, registro, análisis e interpretación de la naturaleza actual" (p. 92).

Continuando con la ruta metodológica, se seleccionó como población a investigar a La Unidad Educativa "Toribio Claure Montaño" que pertenece a la Dirección Distrital de educación de puerto Villarroel. Esta se encuentra en la localidad de la Florida. Este sector se caracteriza por ser una zona rural alejada de la ciudad, sin embargo, la institución cuenta con un total de 750 estudiantes, 66 estudiantes del nivel inicial, 306 estudiantes del nivel primario, y 378 estudiantes del nivel secundaria.

En relación a la muestra de estudio, estuvo compuesta por grupos comunitarios de la institución donde se incluyen docentes, representantes y estudiantes. Sin embargo, para efectos de delimitación del presente estudio, se organizó la experiencia por grupos de trabajo. Para este estudio en específico se tomará en cuenta solamente la actividad realizada con el curso de $1^{\underline{o}} \mathrm{~B}$ de secundaria y para responder al problema planteado, la investigación se llevó a cabo en tres fases que se describen a continuación.

\section{Fase I. Delimitación de la experiencia}

En esta fase de la investigación se delimitó el objeto de estudio luego de un previo entrenamiento y revisión teórica en base al manejo del periódico como herramienta didáctica.

También se llevó a cabo una reunión entre los profesores de la institución con el fin de analizar, planificar y discutir la idea de crear, compartir y comentar nuevas metodologías de enseñanza aprendizaje para los estudiantes. Adicionalmente se comentaron los aspectos de todas las asignaturas del currículo. Como cierre de esta fase, se determinó un calendario de actividades y se diseñaron los instrumentos requeridos para el estudio: guía de entrevistas, matriz de revisión documental, cámara fotográfica, entre otros.

\section{Fase II. Ejecución de la propuesta}

Para la ejecución de la propuesta se seleccionó al primer grupo de muestra para la aplicación de la estrategia. En esta fase se realizó el 
trabajo de campo, es decir, se les enseñó a los participantes cómo aprovechar el periódico como estrategia de enseñanza. Posteriormente se realizaron las entrevistas y se organizaron los grupos de discusión. Para cerrar esta fase, se realizó una transcripción y registro de la información recopilada con lo que escribió un primer borrador del documento de sistematización.

\section{Fase III. Análisis de resultados}

En esta tercera fase, el proceso estuvo orientado a ordenar, procesar y analizar la información recopilada de las entrevistas, grupos de discusión, testimonios de vida y fuentes documentales.

Las impresiones obtenidas de la aplicación de cada una de las estrategias fueron organizadas en una matriz de datos a modo de tablas o cuadros. Adicionalmente también se seleccionaron las fotografías y se realizó una revisión general por parte del equipo de sistematización, tomando en cuenta todos los resultados obtenidos en la fase anterior con lo que pudo redactar el Trabajo Final.

\section{RESULTADOS Y DISCUSIÓN}

continuación, se describen los resultados obtenidos en la
realización de esta investigación desde la perspectiva de cada
una de las fases anteriormente descritas.

\section{Fase I. Delimitación de la experiencia}

Una vez delimitado el objeto de estudio para comenzar con la propuesta, se decidió comenzar por el 1er grado B de secundaria. Posterior a esta selección, se conversó con el resto de la comunidad educativa con el fin de organizar la propuesta. Se realizaron una serie de entrevistas y reuniones para poder explicar los caminos, formas y maneras de poder elaborar el material didáctico. También se llegó a la conclusión de lo importante que es el proceso de planificación que se estaba realizando para defender la propuesta, ya que ésta permite reorganizar y estructurar el proceso de planificación y ejecución de la enseñanza y de esta forma brindar un una metodología diferente, más práctica y más significativa.

Cabe destacar que la coordinación y comunicación con la comunidad educativa, en un principio fue un tanto dificultoso, pero al pasar del tiempo las cosas fueron fluyendo y mejorando. Esta mejoría fue a razón de que se despejaron las dudas y se superaron las 
carencias de conocimientos de algunos padres de familia sobre la elaboración, aplicación e importancia de los materiales didácticos. De este modo, a medida que se fue explicando la importancia la actividad, el interés de toda la comunidad educativa se despertó y se logró que comprendieran que la participación de toda la comunidad educativa e instituciones mejora la calidad de la educación.

Esta experiencia quedó registrada en la entrevista que se puede apreciar en la Tabla 1 respecto a la siguiente pregunta de encuesta: ¿Cómo fue la coordinación a nivel de comunidad Educativa y otras instituciones?

Tabla 1. ¿Cómo fue la coordinación a nivel de comunidad Educativa y otras instituciones?

\begin{tabular}{ll}
\hline Encuestado & Opinión \\
\hline $\begin{array}{l}\text { Doña Carmen } \\
\text { (Representante) }\end{array}$ & $\begin{array}{l}\text { "existe muy poca participación ya que están } \\
\text { dispersos, esto en relación con las instituciones y } \\
\text { comunidad; entre director, profesores y } \\
\text { estudiantes la coordinación es muy buena" }\end{array}$ \\
$\begin{array}{l}\text { Jimena Franco } \\
\text { (Docente) }\end{array}$ & $\begin{array}{l}\text { "la coordinación entre comunidad educativa y } \\
\text { otras instituciones es regular." }\end{array}$ \\
$\begin{array}{l}\text { Elio Torrico } \\
\text { (Docente) }\end{array}$ & $\begin{array}{l}\text { "coordinación en un principio no hubo porque no } \\
\text { cuando la entendieron se fueron integrando a la } \\
\text { experiencia desarrollada." }\end{array}$ \\
\hline
\end{tabular}

Por tanto, de esta experiencia es posible decir que la coordinación conlleva a planificar y elaborar mejor los propósitos, ya que son puentes de comunicación y diálogo entre seres humanos racionales. Fue imprescindible la comunicación constante para que todos los participantes se hicieran partícipes del hecho.

\section{Fase II. Ejecución de la propuesta:}

Al momento de realizar la actividad el maestro se dirigió al grupo de forma ordenada y coherente para señalar las normas a seguir para hacer la actividad. También se organizaron los grupos de trabajo y el procedimiento comenzó cuando el docente terminó de explicar cómo se elabora el material didáctico, el uso de los periódicos, el recortar las imágenes y armar el esquema en el papelógrafo con el pegamento y los otros recursos. Una vez culminado el collage fue momento de exponerlo y realizar su respectiva explicación según las imágenes y el 
concepto de cada equipo. Posteriormente se realizó la evaluación de lo expuesto respectivamente.

Como resultado a esta experiencia se resaltan a continuación en la tabla 2 los discursos más relevantes de los participantes donde se les preguntó: ¿Cómo se desarrolló la experiencia?

Tabla 2. ¿Cómo se desarrolló la experiencia?

\begin{tabular}{ll}
\hline Encuestado & Opinión \\
\hline $\begin{array}{l}\text { Doña Carmen } \\
\text { (Representante) }\end{array}$ & $\begin{array}{l}\text { "en un principio el desarrollo fue con mucha emoción, ya } \\
\text { elaboración del material didáctico... también me encanta } \\
\text { participar en actividades y siempre apoyar a mis hijos." }\end{array}$ \\
$\begin{array}{l}\text { Profa. Jimena } \\
\text { (Docente) }\end{array}$ & $\begin{array}{l}\text { "la experiencia se desarrolla de manera activa en cada } \\
\text { aula y con mucha coherencia" }\end{array}$ \\
$\begin{array}{l}\text { Elio Torrico } \\
\text { (Docente) }\end{array}$ & $\begin{array}{l}\text { "la experiencia se ha ido desarrollando de forma } \\
\text { comunicativa porque poco a poco los padres de familia }\end{array}$ \\
& se han ido integrando."
\end{tabular}

Otro aspecto importante a resaltar en estos resultados fue la percepción que tuvieron los representantes y los estudiantes con respecto a la actividad. En las siguientes tablas con el número 3 y 4 se demuestran las opiniones más relevantes acerca de las preguntas ¿Cómo han reaccionado las madres y padres de familia ante la actividad? Y ¿Cómo reaccionaron los estudiantes ante la actividad?

Tabla 3. ¿Cómo han reaccionado las madres y padres de familia ante la actividad?

\begin{tabular}{ll}
\hline Encuestado & Opinión \\
\hline $\begin{array}{l}\text { Doña Carmen } \\
\text { (Representante) }\end{array}$ & $\begin{array}{l}\text { "es un trabajo muy productivo y de gran repercusión } \\
\text { en lostudiantes, ya que con este tipo de actividades } \\
\text { no solo el no solo el maestro ve el desempeño de los } \\
\text { estudiantes, si no también somos partícipes los papás" }\end{array}$ \\
$\begin{array}{ll}\text { Jimena Franco } \\
\text { (Docente) }\end{array}$ & $\begin{array}{l}\text { "en realidad algunos apoyan la noción de dicha } \\
\text { actividad pero otros no." }\end{array}$ \\
$\begin{array}{l}\text { Elio Torrico } \\
\text { (Docente) }\end{array}$ & $\begin{array}{l}\text { "la reacción de los padres de familia fue buena porque } \\
\text { pudieron apreciar el trabajo elaborado por sus hijos." }\end{array}$
\end{tabular}


De esta forma ante la mirada de los padres de familia, la elaboración del material didáctico en base a imágenes de periódico está siendo una novedad puesto que antes, la enseñanza era en base a libros y conceptos científicos elaborados por el maestro, el cual desarrollaba en los estudiantes una simple memorización y repetición. Así mismo el apoyo de los padres de familia debe ser de forma coordinada ya que ellos son y serán siempre, parte del proceso de enseñanza aprendizaje de sus hijos.

Tabla 4. ¿Cómo reaccionaron los estudiantes ante la actividad?

\begin{tabular}{ll}
\hline Encuestado & Opinión \\
\hline $\begin{array}{l}\text { Doña Carmen } \\
\text { (Representante) }\end{array}$ & $\begin{array}{l}\text { "los estudiantes realizaron la actividad de forma } \\
\text { acelerada por los ánimos, las inquietudes, llenos de } \\
\text { nerviosismo, pero sacando adelante su tema de } \\
\text { exposición, una vez terminada la exposición ellos } \\
\text { perdieron su temor y timidez, se soltaron y estuvieron } \\
\text { más expresivos." }\end{array}$ \\
$\begin{array}{l}\text { Jimena Franco } \\
\text { "el cambio en los estudiantes resulta una gran }\end{array}$ \\
$\begin{array}{l}\text { Elio Torrico } \\
\text { (Docente) }\end{array}$ & $\begin{array}{l}\text { "la reacción fue muy positiva porque los trabajos que } \\
\text { realizaron fueron de manera dinámica y cooperativa. } \\
\text { (...) ya que para ellos es un desafío el elaborar un }\end{array}$ \\
& $\begin{array}{l}\text { tema en base a recortes de imágenes, donde la } \\
\text { producción y socialización del conocimiento son }\end{array}$ \\
& comunitarias."
\end{tabular}

En este aspecto es preciso decir entonces que los estudiantes en un principio reaccionaron extrañados ante el desarrollo de la actividad, puesto que para ellos era un método de transmisión de conocimiento muy diferente al que acostumbraban llevar en el aula. Posteriormente le tomaron gusto a la actividad porque empezaron a investigar, recortar y formular sus propios conceptos. En consecuencia, se produjo una retroalimentación donde el maestro aprende de lo que saben los estudiantes y viceversa.

\section{Fase III. Análisis de resultados}

En esta tercera fase, posteriormente al análisis de los resultados se pudo deducir cuáles fueron los alcances y las limitaciones que ocurrieron durante el proceso, ya que surgieron 
algunas complicaciones y por lo tanto, mecanismos de respuesta para solucionar dichas situaciones.

En cuanto a los logros, se pueden apreciar de forma concreta en la experiencia de los participantes al responder la siguiente pregunta de encuesta: ¿Qué cambios han tenido los estudiantes luego de la experiencia? Este resultado se refleja a continuación en la tabla 5.

Tabla 5. ¿Qué cambios han tenido los estudiantes luego de la experiencia?

\begin{tabular}{ll}
\hline Encuestado & Opinión \\
\hline $\begin{array}{l}\text { Doña Carmen } \\
\text { (Representante) }\end{array}$ & $\begin{array}{l}\text { "una vez terminada la exposición ellos perdieron su } \\
\text { temor y timidez, es decir se soltaron y estuvieron más } \\
\text { expresivos, esto ayuda mucho a desenvolverse frente al } \\
\text { público." }\end{array}$ \\
$\begin{array}{l}\text { Jimena Franco } \\
\text { (Docente) }\end{array}$ & $\begin{array}{l}\text { "los cambios que se dieron fueron la perdida de timidez } \\
\text { Elio Torrico }\end{array}$ \\
$\begin{array}{l}\text { (Docente) } \\
\text { "Los cambios que tuvieron los estudiantes es que ya } \\
\text { contaban con material didáctico y la motivación del } \\
\text { alumno mejoró en su aprendizaje." }\end{array}$ \\
\hline
\end{tabular}

Por consiguiente, se ha logrado que un mayor porcentaje de educandos mejoraron la cooperación y coordinación en forma grupal, donde los educandos pueden manipular los libros, recorte de imágenes y elaboración del material de apoyo en las diferentes actividades. Se logró construir un material didáctico que apoyó la experiencia del educando.

En cuanto a las dificultades que tuvo que afrontar la investigación se reflejan en los testimonios más relevantes que se muestran a continuación en la tabla 6 donde los encuestados responden: ¿Qué dificultades han tenido en la sistematización de la experiencia? 
Tabla 6. ¿Qué dificultades han tenido en la sistematización de la experiencia?

\begin{tabular}{ll}
\hline Encuestado & Opinión \\
\hline $\begin{array}{l}\text { Doña Carmen } \\
\text { (Representante) }\end{array}$ & $\begin{array}{l}\text { "faltó la profundización del tema a exponer, la falta de } \\
\text { recursos didácticos por vivir en un área rural, y la falta } \\
\text { de organización por vivir en lugares alejados hace que } \\
\text { no se concrete o que sea difícil de concretar una } \\
\text { actividad según nuestras expectativas." }\end{array}$ \\
$\begin{array}{l}\text { Jimena Franco } \\
\text { (Docente) }\end{array}$ & $\begin{array}{l}\text { "las dificultades más latentes fueron la falta de apoyo } \\
\text { mismos colegas." } \\
\text { Elio Torrico } \\
\text { (Docente) }\end{array}$ \\
& $\begin{array}{l}\text { los principales dificultades fueron en la adquisición de } \\
\text { geográfica de nuestra zona que es un poco alejado de la } \\
\text { ciudad." }\end{array}$ \\
\hline
\end{tabular}

Las dificultades más sobresalientes que se presentaron fueron la falta de periódicos, por ser un lugar alegado del pueblo y por no contar con un puesto de venta de periódicos como sucede en la ciudad. También la falta de tiempo que corresponde para la elaboración del papelógrafo, para el cual se necesita por lo menos toda una mañana para poder realizarlo. Aunado a esta carencia, estuvo la participación del conjunto de Padres de familia porque a muchos no les interesa siquiera si sus hijos están bien o no en la escuela. También se puede considerar la falta de coordinación entre docentes ya que a muchos no interesa ser partícipes de las actividades. Otra de las carencias fue el poco hábito de lectura por la falta de centros de biblioteca por el sector.

Sin embargo, y a pesar de todas esas limitaciones las mismas fueron afrontadas y por lo tanto se pudo llevar a cabo la actividad. Esto se evidencia en la siguiente tabla identificada con el número 7 donde los encuestados respondieron ¿Cómo solucionaron las dificultades? 
Tabla 7. ¿Cómo solucionaron las dificultades?

\begin{tabular}{ll}
\hline Encuestado & Opinión \\
\hline $\begin{array}{l}\text { Doña Carmen } \\
\text { (Representante) }\end{array}$ & "se solucionaron buscando otras alternativas." \\
$\begin{array}{ll}\text { Jimena Franco } \\
\text { (Docente) }\end{array}$ & $\begin{array}{l}\text { "se dio soluciones con la conversación y planteando } \\
\text { nuevas estrategias de enseñanza para el aprendizaje de } \\
\text { los estudiantes." }\end{array}$ \\
$\begin{array}{l}\text { Elio Torrico } \\
\text { (Docente) }\end{array}$ & $\begin{array}{l}\text { "se solucionó como se ha podido puesto que, con un poco } \\
\text { de sacrificio se puede todo." }\end{array}$
\end{tabular}

Por consiguiente, las dificultades se solucionaron con el diálogo y entendimiento, y también planteando nuevas formas de enseñanza con los padres de familia. Es posible decir que no hay trabas ni obstáculos para el que quiere cambio y la superación constante.

Por tanto, con esta actividad se logró que los estudiantes puedan razonar y reflexionar críticamente para su formación personal, como también en la toma de decisiones. La Mediación del maestro es muy importante en el proceso de la experiencia sistematizada en la enseñanza del aprendizaje significativo e integral en los educandos del Colegio Toribio Claure Montaño.

\section{La vivencia pedagógica}

Los resultados de esta investigación fueron bastante satisfactorios porque se logró la meta propuesta. De este modo, los estudiantes participaron activamente ante la iniciativa de cambio en el empleo de un material didáctico, el cual hizo posible que todos participaran de manera activa en la elaboración de dicho material, el cual viabilizó el trabajo comunitario, promoviendo el interés y la conducta investigativa en los educandos, logrando examinar los aspectos positivos de la utilización del periódico como material didáctico. A la vez los estudiantes pudieron razonar y reflexionar críticamente para su formación personal, como también en la toma de decisiones.

Ante esta situación afirman los docentes que participaron en esta experiencia, incluyendo al investigador: "nos sentimos contentos porque incentivamos el uso y aplicación del periódico como material educativo y de apoyo en la enseñanza-aprendizaje de todos los estudiantes de la Unidad Educativa Toribio Claure Montaño". 
Dicho esto, durante la experiencia es relevante aplicar la función analógica, la cual se entiendo como la capacidad de los materiales educativos para ayudar a los procesos cognitivos, a comprender o asimilar un conocimiento generando una ejemplificación o simulación concreta (visual, auditiva u otra) de conocimientos complejos. Así, los materiales educativos que sólo trabajaban esta función, han sido sobretodo analogías de esos conocimientos plasmados de manera concreta para motivar y atraer la atención de los sentidos, mejorando las relaciones cognitivas que permiten la comprensión de ese conocimiento. Estos materiales hechos en función analógica generalmente han sido producidos por los maestros para construir una experiencia educativa, cuya base de aprendizaje sea propiamente el material educativo". (Unidad de formación № 72013 p.15)

Con esta actividad metodológica de elaboración del material educativo se evidenciaron educandos entusiasmados, que trabajaron en la elaboración del material didáctico porque para ellos era un método de transmisión de conocimiento muy diferente al que acostumbraban llevar en el aula. El cambio en los estudiantes resulta una gran emoción porque es algo novedoso, llamativo y fácil de hacer tanto en la exposición y con ella se logra un aprendizaje significativo. Así reaccionaron positivamente ante los trabajos realizados el cual fue de manera dinámica y cooperativa.

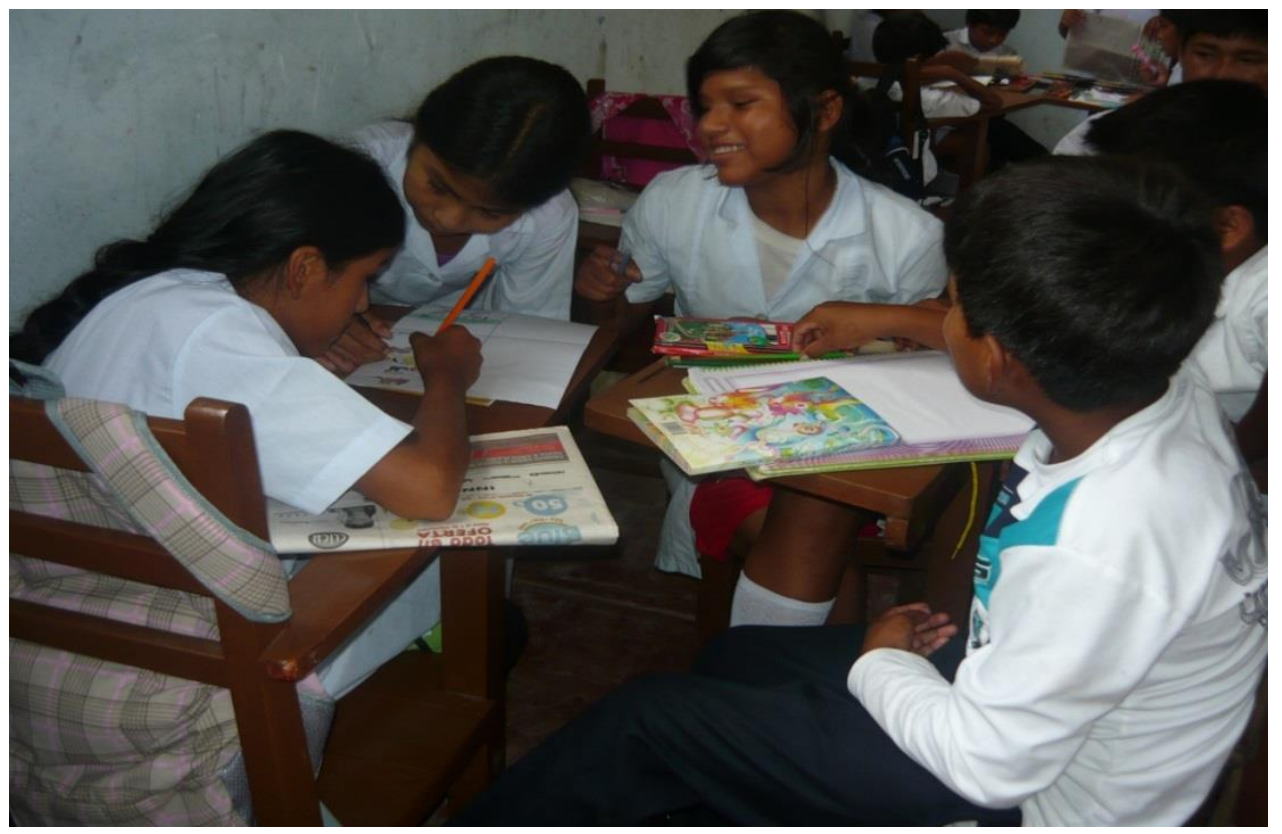

Figura 1. Demostración de entusiasmo y seguridad en los estudiantes al realizar el material didáctico. (Fuente: autoría propia) 


\section{CONCLUSIONES}

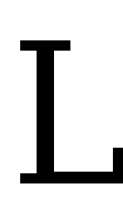

a elaboración de estos materiales didácticos con recursos del medio, proporcionan experiencias que los educandos pueden aprovechar para identificar propiedades, clasificar, establecer semejanzas y diferencias, resolver problemas, entre otras y, al mismo tiempo, sirve para que los docentes se interrelacionen de mejor manera con sus estudiantes, siendo entonces la oportunidad para que el proceso de enseñanza-aprendizaje sea más profundo. El uso de material concreto ofrece a los estudiantes la posibilidad de manipular, indagar, descubrir, observar, al mismo tiempo que se ejercita la práctica de normas de convivencia y el desarrollo de valores como, por ejemplo: la cooperación, solidaridad, respeto, tolerancia, la protección del medioambiente, entre otros.

Con esta actividad se logró que maestros puedan construir nuevas estrategias innovadoras de aprendizaje o reconstruir con nuevas ideas creativas para un aprendizaje significativo. A los padres, alumnos y profesores les parece muy interesante esta metodología porque a través de ella, sus hijos formulan sus propios conceptos y conocimientos sobre los temas desarrollados en las clases.

Por tanto, con esta actividad se logró que los estudiantes puedan razonar y reflexionar críticamente para su formación personal, como también en la toma de decisiones. Con los objetivos logrados los estudiantes estarán aptos para sistematizar las experiencias vividas en el campo educativo y en su diario vivir. Los cambios fueron el trabajo comunitario, promoviendo el interés y la conducta investigativa en los estudiantes, logrando examinar los aspectos positivos de la utilización del periódico como material didáctico. La experiencia educativa partió de la práctica seguido de la teorización, evaluación y producción, respondiendo al nuevo enfoque.

Por otro lado, los cambios que se dieron fueron la perdida de timidez y que a la vez lograron dialogar entre ellos. Por consiguiente, se ha tenido un logro de un mayor porcentaje de educandos mejoraron la cooperación y coordinación en forma grupal, donde los educandos puede manipular los libros, recorte de imágenes y elaboración del material de apoyo en las diferentes actividades. Se estimularon así mismo las investigaciones sobre los diferentes temas abordados por los docentes, lo cual les ayudara a desarrollar la dimensión del ser, saber, hacer y el decidir y de esta forma; generar estudiantes reflexivos, críticos, creativos y productivos, capaces de argumentar y comunicar. 
Además con esta estrategia se logró establecer relaciones de correspondencia, clasificación, ordenamiento, identificación de idénticos, pertenencia, asociación; reconocer características de tamaños, formas, colores, sensaciones, olores, sabores, sonidos, entre otras. Pero quizás uno de los logros más relevantes fue el de despertar la motivación de toda la comunidad educativa que participó en esta actividad. De este modo, con la motivación de hacer las cosas, serán capaces de lograr con mayor facilidad las metas que se propongan.

Por consiguiente, la motivación es el lazo que une esa acción a satisfacer necesidades o conveniencias. Gracias a esta cualidad, los estudiantes se convierten en participantes activos a la hora de aprender. Ellos pueden aprender haciendo, construyendo, escribiendo, diseñando, creando, resolviendo, haciendo preguntas y alimentando la curiosidad.

Se considera que este tipo de actividades, anima a los estudiantes a sugerir aproximaciones a un problema o a adivinar los resultados de un experimento. "motivar y atraer la atención de los sentidos, mejorando las relaciones cognitivas que permiten la comprensión de ese conocimiento." En ese sentido, el material educativo son todos los objetos (incluso los simbólicos como un software educativo) que sirven para educar, no sólo para transmitir conocimientos sino también para producirlos. (Unidad de Formación № 7 p. 7 y 12)

\section{REFERENCIAS}

Gaceta Oficial del Estado Plurinacional de Bolivia (2010) Ley No. 070 Ley de la educación "Avelino Siñani - Elizardo Pérez"

Hernández-Sampier, R., Fernández C., C. y Baptista L., P. (2014). Metodología de la Investigación. (6ta. ed.). México: McGrawHill Interamericana

Ministerio de Educación (2013) Unidad de Formación $\mathrm{N}^{\circ} 5$ Estrategias Metodológicas para el Desarrollo Curricular. Programa de estudio. La Paz, Bolivia

Ministerio de Educación (2013). Unidad de Formación No. 7 "Producción de Materiales Educativos". Cuadernos de Formación Continua. Equipo PROFOCOM. La Paz, Bolivia

Palella, S. y Martins, F. (2010). Metodología de la investigación Cuantitativa. Caracas: Fondo Editorial de la Universidad Pedagógica Experimental Libertador FEDUPEL

Taylor S.J. (1992) Introducción a los métodos cualitativos en investigación. La búsqueda de los significados. Editorial Paidós, España 